\title{
Apnea Time
}

National Cancer Institute

\section{Source}

National Cancer Institute. Apnea Time. NCI Thesaurus. Code C158354.

A measurement of the apnea duration determined by total sleep time minus the sum of inspiration time and expiration time. 